\title{
Duration of Lactation and Risk Factors for Maternal Cardiovascular Disease
}

\author{
Eleanor Bimla Schwarz, MD, MS ${ }^{1}$, Roberta M. Ray, $\mathbf{M S}^{2}$, Alison M. Stuebe, MD, MSc ${ }^{3}$, \\ Matthew A. Allison, MD, MPH ${ }^{4}$, Roberta B. Ness, MD, MPH ${ }^{5}$, Matthew S. Freiberg, MD, \\ $\mathrm{MSc}^{1}$, and Jane A. Cauley, $\mathrm{DrPH}^{6}$ \\ ${ }_{1}^{1}$ Assistant Professor of Medicine, University of Pittsburgh, 230 McKee Place, Suite 600 Pittsburgh, \\ PA 15213 \\ 2 Statistical Research Associate Division of Public Health Sciences, Fred Hutchinson Cancer \\ Research Center, Seattle, WA 98109 \\ ${ }^{3}$ Assistant Professor of Obstetrics and Gynecology, Division of Maternal-Fetal Medicine, University \\ of North Carolina School of Medicine, Chapel Hill, NC 27599 \\ ${ }^{4}$ Assistant Professor University of California San Diego 8950 Villa La Jolla Drive, Suite B122 \\ Mailcode 0811 La Jolla, CA 92037 \\ ${ }^{5}$ Professor of Epidemiology, Graduate School of Public Health, University of Pittsburgh. 130 DeSoto \\ Street, Crabtree A524. Pittsburgh, PA 15261 \\ ${ }^{6}$ Professor of Epidemiology. University of Pittsburgh Graduate School of Public Health. 130 DeSoto \\ Street, Crabtree A524. Pittsburgh, PA 15261
}

\section{Abstract}

Objective: To examine dose-response relationships between the cumulative number of months women lactated and postmenopausal risk factors for cardiovascular disease.

Methods: We examined data from 139,681 postmenopausal women (median age 63 years) who reported at least 1 live birth upon enrolling in the Women's Health Initiative (WHI) observational study or controlled trials. Multivariable models were used to control for sociodemographic (age, parity, race, education, income, age at menopause), lifestyle, and family history variables when examining the impact of duration of lactation on risk factors for cardiovascular disease, including obesity (body mass index(BMI) at or above 30), hypertension, self-reported diabetes, hyperlipidemia, prevalent and incident cardiovascular disease.

Results: Dose-response relationships were observed; in fully-adjusted models, women who reported a lifetime history of more than 12 months of lactation were less likely to have hypertension $(\mathrm{OR}=0.88, \mathrm{p}<0.001)$, diabetes $(\mathrm{OR}=0.80, \mathrm{p}<0.001)$, hyperlipidemia $(\mathrm{OR}=0.81, \mathrm{p}<0.001)$ or cardiovascular disease $(\mathrm{OR}=0.91, \mathrm{p}=0.008)$ than women who never breastfed, but they were not less likely to be obese. In models adjusted for all above variables and BMI, similar relationships were seen. Over an average of 7.9 years of postmenopausal participation in the WHI, women with a single live birth who breastfed for 7-12 months were significantly less likely to develop cardiovascular disease (HR 0.72 (0.53 to 0.97)) than women who never breastfed.

Corresponding Author: Eleanor Bimla Schwarz, MD, MS Assistant Professor of Medicine, Epidemiology, Obstetrics, Gynecology, and Reproductive Sciences University of Pittsburgh Center for Research on Health Care 230 McKee Place, Suite 600 Pittsburgh, Pa 15213 Phone (412) 586-9836 Fax (412) 692-4838 E-mail: Schwarzeb@upmc.edu.

Financial Disclosure: The authors did not report any potential conflicts of interest. 
Conclusion: Among postmenopausal women, increased duration of lactation was associated with a lower prevalence of hypertension, diabetes, hyperlipidemia and cardiovascular disease.

\section{Introduction}

Cardiovascular disease (CVD) is the leading cause of death for women in developed nations. As such, it is important to identify behaviors that modify women's risk of CVD. Diet and exercise are widely known to impact CVD, but less is known about the impact a woman's decision to breastfeed her children may have on her future risk of CVD. While breastfeeding is widely acknowledged to benefit infant health, in 2004, only $11 \%$ of US mothers exclusively breastfed their infants for the first six months of the infant's life.(1)

Lactation increases a mother's metabolic expenditure by an estimated $480 \mathrm{kcal} / \mathrm{day}$;(2) lactating mothers lose more weight in the postpartum period than women who do not breastfeed.(3) Active lactation has been shown to improve glucose tolerance,(4) lipid metabolism(5) and C reactive protein.(6) Recently, a number of studies have indicated longer range effects of lactation. $(7,8)$

Whether lactation actually decreases risk of cardiovascular disease and whether the benefits of lactation persist after menopause is unclear. The goal of this study was therefore, to examine the impact of lactation on subsequent risk of obesity, hypertension, diabetes, hyperlipidemia and CVD among 139,681 post-menopausal women.

\section{Materials and Methods}

The Women's Health Initiative (WHI) began in 1994 and consisted of a set of clinical trials and an observational study focused on strategies for preventing chronic disease in postmenopausal women. Detailed descriptions of the design of the WHI and the baseline characteristics of the participants have been previously published. $(9,10)$ Briefly, the WHI involved 161,808 generally healthy postmenopausal women who were 50 to 79 years of age on enrollment. Methods regarding data collection, data management, and assurance of the quality of the data have been published previously. $(11,12)$ At a baseline clinic visit, each woman completed questionnaires regarding medical, reproductive, and family history, medication use, and lifestyle. Participants were then sent annual medical update forms to report any hospitalizations. The occurrence of a wide variety of other outcomes, including myocardial infarction, was also assessed with annual questionnaires. Confirmation of hospitalization and other reported outcomes was based on medical record review.(12) All deaths caused by coronary disease were adjudicated using death certificates, available medical records, and descriptions of events. As of September 2005, for participants in the WHI observational study (OS) and controlled trials (CT) the median duration of follow-up was 7.9 years. At that time, $4.7 \%$ and $4.6 \%$ of subjects had withdrawn or were alive but lost to follow-up from the OS and CT respectively.

Lactation history was assessed when women enrolled in the WHI by asking women who reported $\geq 1$ live birth, "Did you breastfeed or nurse any children for at least one month?" Women who responded "yes," were then asked "Thinking about all the children you breastfed, how many months total did you breastfeed? (your best guess)." These responses were then recorded as a categorical variable (none, 1-6 months, 7-12 months, 13-23 months, and $\geq 24$ months) indicating cumulative lifetime duration of lactation. Age at last lactation was also ascertained as a categorical variable $(<20,20-24,25-29,30-34,35-39,40-44$, and $\geq 45)$. To estimate years between last lactation and WHI enrollment, we assigned each woman a midinterval value as the age she last lactated and subtracted this value from age at WHI enrollment. 
In this study we examined five cardiovascular risk factors identified at the baseline clinic visit: obesity, hypertension, diabetes, hyperlipidemia, and a history of CVD prior to enrolling in the WHI. In addition we examined incident CVD over the 7.9 years WHI participants were followed. All incident CVD (coronary heart disease, stroke, congestive heart failure, angina, peripheral vascular disease, carotid artery disease, and coronary revascularization) was validated by physician adjudication using standardized protocols.(12)

Obesity was measured using a body mass index (BMI) calculated from height and weight collected by study staff at baseline clinic visits. When considering obesity as a dependent variable, we compared women whose BMI was $\geq 30$ to those women whose BMI was $<30$. Women with hypertension were identified as those with a self-reported history of treated hypertension or blood pressure measurements meeting criteria for hypertension.(13) Women with diabetes or hyperlipidemia were identified by self-reported history of need to use a medication to control "sugar diabetes" or "cholesterol." Medication use was validated on enrollment by nurse examination of medication bottles which subjects were instructed to bring to the enrollment visit. For a subset of women, serum lipid levels were drawn and used to confirm self-reported hyperlipidemia. Women with CVD on enrollment were identified by a self-reported history of myocardial infarction, angina, congestive heart failure, peripheral arterial disease, revascularization, carotid angioplasty, carotid endarterectomy or stroke.

On enrollment, dietary information was collected using a 120-item semi-quantitative food frequency questionnaire developed for the WHI. When adjusting for diet in these analyses, we considered energy, cholesterol, fat, fiber, and sodium intakes. Data on use of aspirin, multivitamins, tobacco, and postmenopausal hormone therapy was also reported on enrollment. Physical activity was also reported on enrollment questionnaires that elicited total hours per week engaged in a specified list of moderate to vigorous activities. The reproducibility and validity of WHI measures of physical activity have been previously described(14).

Observational study participants also reported their weight at age 18 and at birth and whether they had been breastfed themselves as an infant.

We excluded subjects who were nulliparous $(\mathrm{n}=19202)$ or for whom information on parity $(n=973)$ or duration of lactation $(n=1705)$ was missing. We also excluded 247 parous women who reported only stillbirths.

For each of the 5 outcomes assessed at baseline (obesity, hypertension, hyperlipidemia, diabetes, and a history of CVD), we first examined unadjusted relationships between any history of lactation and then duration of lactation, and the prevalence of cardiovascular risk factors. We then constructed multivariable logistic regression models to examine the relationship between duration of lactation and each of these outcomes while adjusting for sociodemographic variables (age, parity, race/ethnicity, income, education). Next we examined models additionally adjusted for lifestyle variables (diet, physical activity, smoking, use of postmenopausal hormone therapy, aspirin, or a multivitamin) and family history (of diabetes, myocardial infarction, or stroke).

As obesity has been closely linked to CVD,(15) for all outcomes other than obesity, we further examined models adjusted for all of the above variables and BMI (measured using categories of $\mathrm{BMI}<25,25$ to $<30$, and $\geq 30$ ). As weight at age 18 , birth weight, and whether a woman was breastfed herself in infancy(15) may also affect subsequent risk of CVD, we examined the relationship between duration of lactation and each of these outcomes when these additional self-reported variables were added to models.

We used Cox proportional hazard models to compute hazard ratios (HR) for incident CVD, adjusting for covariates as described above. The proportional hazards assumption was met by testing for interaction of lactation duration with the time variable. In addition, we performed 
an analysis in which we examined the subgroup of 126,020 women who reported no CVD on enrolling in the WHI.

As prior work has shown that the benefits of lactation may decrease with time since lactation, (7) and that there is significant racial variation in rates of breastfeeding,(16) we examined our data stratified by age, age at last lactation, parity and race.

Finally, we used multivariate generalized linear models to estimate adjusted prevalence ratios. For all models, to test for dose-response relationships, we examined linear trends across categories of increasing duration of lactation by modeling the categorical breastfeeding duration variable as a continuous variable. All analyses were conducted using SAS version 9.1 (SAS Institute, Cary, NC). Participants with missing covariate data were dropped from analyses involving that covariate. The Institutional Review Board of the University of Pittsburgh approved this study.

\section{Results}

This analysis included 139,681 women with $\geq 1$ live birth and no missing information on lactation $(59,769$ women who participated in the WHI CT, 79,912 who participated in the WHI OS). Sociodemographic characteristics of the post-menopausal study participants are shown in table 1 . The majority of patients (58\%) reported some history of lactation, but only $6 \%$ had a cumulative history of lactation greater than 24 months. Few women reported $12+$ months of lactation per live birth. On average, 35 years had passed since women had lactated when they enrolled in the WHI.

On enrollment in the WHI, 30\% of women were obese (BMI $\geq 30$ ). In age-adjusted analyses, we found parous women were more likely to be obese or hypertensive than nulliparous women. However, parous women who had lactated were less likely to be obese or have hypertension than parous women who had not lactated. In similar, age-adjusted models, we found the prevalence of diabetes and hyperlipidemia was not significantly different among nulliparous or parous women who had lactated. However, parous women who had not lactated were more likely to have diabetes or hyperlipidemia than parous women who had lactated.

Table 2 shows the relationship between duration of lactation and obesity among parous women. Increasing duration of lactation was associated with a lower prevalence of obesity in the univariable model and in the model adjusted for sociodemographic variables. After additional adjustment for lifestyle and family history variables, however, we did not find a significant relationship between 6 or less, or 24+ months lactation and prevalence of post-menopausal obesity; with 7-23 months of lactation there was a trend towards less obesity $(\mathrm{p}=0.07)$.

Increasing duration of lactation was associated with a reduced prevalence of cardiovascular risk factors including hypertension, diabetes, and hyperlipidemia, even after adjustment for sociodemographic variables, lifestyle variables, family history, and BMI category ( $\mathrm{p}<0.01$ for all tests for trend, table 3). Similarly, increasing duration of lactation was associated with a lower prevalence of CVD prior to enrolling in the WHI ( $p<0.01$ for all tests for trend, table 4). Women who reported a lifetime history of more than 12 months of lactation were less likely to have hypertension $(\mathrm{OR}=0.88, \mathrm{p}<0.001)$, diabetes $(\mathrm{OR}=0.80, \mathrm{p}<0.001)$, hyperlipidemia $(\mathrm{OR}=0.81, \mathrm{p}<0.001)$ or cardiovascular disease $(\mathrm{OR}=0.91, \mathrm{p}=0.008)$ than women who never breastfed. When compared to women who had never breastfed, women who reported a cumulative lifetime duration of lactation of $\geq 13$ months were less likely to have developed CVD prior to enrolling in the $\mathrm{WHI}(\mathrm{OR}=0.91,95 \% \mathrm{CI}=0.85$ to $0.98, \mathrm{p}=0.008)$. Based on multivariate adjusted prevalence ratios from generalized linear models, we estimate that among parous women who did not breastfeed compared to those who breastfed for more than 12 months, $42.1 \%$ vs. $38.6 \%$ would have hypertension, $5.3 \%$ vs. $4.3 \%$ would have diabetes, $14.8 \%$ 
vs. $12.3 \%$ would have hyperlipidemia, and 9.9 vs. $9.1 \%$ would have developed cardiovascular disease, although $30 \%$ of each group would be obese when postmenopausal.

When examining fully-adjusted models of the duration of lactation and prevalence of CVD, we found no significant interactions between age at last lactation ( $\mathrm{p}$ for interaction $=0.58$ ), race/ ethnicity ( $\mathrm{p}$ for interaction $=0.35$ ), or history of tobacco use ( $\mathrm{p}$ for interaction $=0.65$ ). However, there was a significant interaction with respect to age ( $\mathrm{p}$ for interaction $=0.02$ ). In fully-adjusted analyses stratified by age, we found the cardiovascular benefits of lactation decreased as women aged; women who were 50-59 years of age on enrolling in the WHI who reported a cumulative history of lactation of $\geq 7$ months were significantly less likely to have CVD than similarly-aged women who had never breastfed (OR (95\% CI) $=0.84$ (0.71 to 0.99), 0.80 (0.65 to 0.97 ), and 0.75 ( 0.58 to 0.96 ) for women who had breastfed for 7-12 months, 13-23 months, and 24+ months, respectively). Among women aged 60-69, only those who reported 13-23 months of lactation were significantly less likely than women who had never breastfed to have developed CVD, OR=0.85 (0.75 to 0.96), and among women aged 70-79 there were no significant relationships between duration of lactation and prevalent CVD.

The majority of participants in the WHI OS (58\%) reported they had been breastfed as an infant; when we added this variable to analyses in which we adjusted for weight at age 18 and/ or weight at birth with and in place of BMI category on enrollment in addition to sociodemographic, family history, and other lifestyle variables, we saw similar relationships between duration of lactation and risk of hypertension, diabetes, hyperlipidemia (data available on request). However, the association with CVD was somewhat attenuated and not statistically significant in the smaller population of OS participants.

When we used Cox models to look at incident CVD over the 7.9 years WHI participants had been followed, we found duration of lactation was associated with a decrease in incident CVD in univariable but not adjusted models (table 4). However, again, there was an interaction with age $(\mathrm{p}$ for interaction $=0.04$, without adjusting for BMI category; $\mathrm{p}$ for interaction $=0.06$, with adjustment for BMI category); when we stratified the adjusted model by age, we found more cardiovascular benefits of lactation among younger women. Among women who were 50-59 on enrollment, when compared to women who never lactated, women with a lifetime duration of 7-12 months of lactation were less likely to develop CVD (HR=0.79, 95\% CI 0.66 to 0.94 , without adjusting for BMI category; $\mathrm{HR}=0.80,95 \%$ CI 0.67 to 0.95 , with adjustment for BMI category) as were women with $24+$ months of lifetime lactation (HR $=0.66,95 \%$ CI 0.50 to 0.86 without adjusting for BMI category; $\mathrm{HR}=0.68,95 \%$ CI 0.52 to 0.89 , with adjustment for BMI category), $\mathrm{p}$ for trend among women aged 50-59 on enrollment $=0.001$. Among women who were older than 60 when they enrolled in the WHI, duration of lactation was not associated with incident CVD.

When we stratified the Cox models by parity ( $\mathrm{p}$ for interaction $=0.06$ without adjusting for BMI category, $\mathrm{p}=0.07$ with adjustment for BMI category), we found that when compared to women who never lactated, women with one live birth who breastfed for 7-12 months were significantly less likely to develop CVD (HR 0.72 (0.53 to 0.97), while among women with 2 or 3 live births, lactation was only associated with a significant reduction in incident CVD if the woman reported 24+ months of lactation (for 2 live births, HR=0.58 (0.35 to 0.95), for 3 live births, $\mathrm{HR}=0.78$ (0.63 to 0.98$)$ ).

In analyses of the subgroup of women who had not developed CVD prior to enrolling in the WHI, duration of lactation was not associated with incident CVD. 


\section{Discussion}

This study found that women who breastfed their children were less likely to have developed hypertension, diabetes, hyperlipidemia, or CVD when post-menopausal. Women who reported longer histories of lactation had significantly lower rates of risk factors for CVD even after adjusting for sociodemographic and lifestyle variables, family history, and BMI category. Women who had a cumulative lifetime duration of lactation greater than 12 months were approximately $10 \%$ less likely to have developed CVD than parous women who never breastfed. While the American Academy of Pediatrics, in the interest of promoting child health, recommends breastfeeding for the first 12 months of an infant's life,(17) our study shows this recommendation also benefits maternal health. If a randomized trial were to find similar effect sizes when comparing women who breastfed more than 1 year to those who never breastfed, we roughly estimate the number needed to treat to prevent a case of maternal hypertension would be 29 , to prevent a case of hyperlipidemia would be 40 , to prevent a woman from developing diabetes would be 100 , and to prevent a case of CVD would be 125 . These findings build on a growing body of literature that demonstrates that lactation has beneficial effects on blood pressure,(18) risk of developing diabetes, $(7,8)$ and lipid metabolism.(19) It is known that fat stores accumulate during pregnancy,(20) and prior studies have shown that in populations where breastfeeding is rare, pregnancy may increase risk of CVD.(21) It has been hypothesized that lactation may reduce cardiovascular risk by mobilizing accumulated fat stores. However, our finding that women who breastfed had lower rates of CVD after adjustment for BMI category indicates that lactation does more than simply reduce a woman's fat stores. Hormonal effects, such as those of oxytocin, may have significant effects on cardiovascular profiles. While some have considered lactation's reduction of gonadal hormones to be similar to menopause, which increases risk of CVD, we paradoxically found lactation to protect from CVD, although these benefits appear to wane as women reach 70 years of age, and the time since a woman lactated increases.

Strengths of this study include the large and racially diverse group of women who participated in the WHI. However, all observational studies may be subject to residual confounding. Lifetime duration of lactation, as well as history of diabetes, hyperlipidemia, and prevalent CVD were all self-reported. The measure of lactation used in this study does not allow estimation of the intensity or exclusivity with which women breastfed their infants. It is likely that more powerful effects would be seen with exclusive breastfeeding. Recall or reporting bias may have led to some misclassification of women's lactation history. Prior research has found that women with shorter durations of lactation tended to over-report, while women with longer durations tended to underreport (22). Presuming this misclassification is nondifferential with respect to the outcomes examined, it would attenuate estimates of dose-response associations between duration of lactation and later health. Nonetheless, we observed significant dose-response associations between duration of lactation and risk factors for CVD. Some have hypothesized that women who are able to prolong breastfeeding may lead "less stressful" lives, which may lower their risk of CVD.(23) While we controlled for socioeconomic variables (education, income, race, parity, and tobacco use) which have been associated with life stress,(24) other factors may remain. In addition, studies have linked obesity and insulin resistance to difficulties with breastfeeding,(25) suggesting that decreased duration of lactation could be a marker for an existing abnormal metabolic profile. Regrettably, data on maternal cardiovascular risk at the time of lactation was not collected by the WHI. Women who were breastfed by their mothers may be more likely to breastfeed their children. (26) If early life exposure to breast milk affects cardiovascular risk profiles later in life, models without this variable may be subject to residual confounding. Our models which included this variable were similar to other estimates, in keeping with other recent studies that have provided little evidence of a protective influence of being breastfed on CVD risk factors, incidence, or mortality later in life.(27) 
In conclusion, this study shows that lactation may play a significant role in reducing risk of CVD. This implies that recommendations that women breastfeed their infants for the first year of life should be endorsed for the benefit of both maternal and child health.

\section{Acknowledgments}

Funding: The WHI program is funded by the National Heart, Lung, and Blood Institute, National Institutes of Health, U.S. Department of Health and Human Services through contracts N01WH22110, 24152, 32100-2, 32105-6, 32108-9, $32111-13,32115,32118-32119,32122$, 42107-26, 42129-32, and 44221. Dr. Schwarz is funded by the National Institute of Child Health and Development, K23 HD051585.

\section{References}

1. Breastfeeding trends and updated national health objectives for exclusive breastfeeding--United States, birth years 2000-2004. MMWR Morb Mortal Wkly Rep 2007;56:760-3. [PubMed: 17673896]

2. Butte NF, Wong WW, Hopkinson JM. Energy requirements of lactating women derived from doubly labeled water and milk energy output. J Nutr 2001;131:53-8. [PubMed: 11208938]

3. Rooney BL, Schauberger CW. Excess pregnancy weight gain and long-term obesity: one decade later. Obstet Gynecol 2002;100:245-52. [PubMed: 12151145]

4. Yang JQ, Xu YH, Gai MY. Breast-feeding in reducing regular insulin requirement in postpartum for insulin dependent diabetes mellitus and gestational diabetes mellitus. Zhonghua Fu Chan Ke Za Zhi 1994;29:135-7, 188. [PubMed: 8082426]

5. Kjos SL, Henry O, Lee RM, Buchanan TA, Mishell DR Jr. The effect of lactation on glucose and lipid metabolism in women with recent gestational diabetes. Obstet Gynecol 1993;82:451-5. [PubMed: 8355952]

6. Williams MJ, Williams SM, Poulton R. Breast feeding is related to C reactive protein concentration in adult women. J Epidemiol Community Health 2006;60:146-8. [PubMed: 16415265]

7. Stuebe AM, Rich-Edwards JW, Willett WC, Manson JE, Michels KB. Duration of lactation and incidence of type 2 diabetes. Jama 2005;294:2601-10. [PubMed: 16304074]

8. Villegas R, Gao YT, Yang G, Li HL, Elasy T, Zheng W, et al. Duration of breast-feeding and the incidence of type 2 diabetes mellitus in the Shanghai Women's Health Study. Diabetologia 2008;51:258-66. [PubMed: 18040660]

9. Design of the Women's Health Initiative clinical trial and observational study. The Women's Health Initiative Study Group. Control Clin Trials 1998;19:61-109. [PubMed: 9492970]

10. Stefanick ML, Cochrane BB, Hsia J, Barad DH, Liu JH, Johnson SR. The Women's Health Initiative postmenopausal hormone trials: overview and baseline characteristics of participants. Ann Epidemiol 2003;13:S78-86. [PubMed: 14575940]

11. Langer RD, White E, Lewis CE, Kotchen JM, Hendrix SL, Trevisan M. The Women's Health Initiative Observational Study: baseline characteristics of participants and reliability of baseline measures. Ann Epidemiol 2003;13:S107-21. [PubMed: 14575943]

12. Curb JD, McTiernan A, Heckbert SR, Kooperberg C, Stanford J, Nevitt M, et al. Outcomes ascertainment and adjudication methods in the Women's Health Initiative. Ann Epidemiol 2003;13:S122-8. [PubMed: 14575944]

13. Chobanian AV, Bakris GL, Black HR, Cushman WC, Green LA, Izzo JL Jr. et al. The Seventh Report of the Joint National Committee on Prevention, Detection, Evaluation, and Treatment of High Blood Pressure: the JNC 7 report. Jama 2003;289:2560-72. [PubMed: 12748199]

14. McTiernan A, Kooperberg C, White E, Wilcox S, Coates R, Adams-Campbell LL, et al. Recreational physical activity and the risk of breast cancer in postmenopausal women: the Women's Health Initiative Cohort Study. Jama 2003;290:1331-6. [PubMed: 12966124]

15. McTigue K, Kuller L. Cardiovascular risk factors, mortality, and overweight. Jama 2008;299:12601. [PubMed: 18349086]

16. Racial and socioeconomic disparities in breastfeeding--United States, 2004. MMWR Morb Mortal Wkly Rep 2006;55:335-9. [PubMed: 16572102] 
17. Gartner LM, Morton J, Lawrence RA, Naylor AJ, O'Hare D, Schanler RJ, et al. Breastfeeding and the use of human milk. Pediatrics 2005;115:496-506. [PubMed: 15687461]

18. Lee SY, Kim MT, Jee SH, Yang HP. Does long-term lactation protect premenopausal women against hypertension risk? A Korean women's cohort study. Prev Med 2005;41:433-8. [PubMed: 15917038]

19. Ram KT, Bobby P, Hailpern SM, Lo JC, Schocken M, Skurnick J, et al. Duration of lactation is associated with lower prevalence of the metabolic syndrome in midlife-SWAN, the study of women's health across the nation. Am J Obstet Gynecol 2008;198:268e1-6. [PubMed: 18191796]

20. Lain KY, Catalano PM. Metabolic changes in pregnancy. Clin Obstet Gynecol 2007;50:938-48. [PubMed: 17982337]

21. Ness RB, Harris T, Cobb J, Flegal KM, Kelsey JL, Balanger A, et al. Number of pregnancies and the subsequent risk of cardiovascular disease. N Engl J Med 1993;328:1528-33. [PubMed: 8267704]

22. Promislow JH, Gladen BC, Sandler DP. Maternal recall of breastfeeding duration by elderly women. Am J Epidemiol 2005;161:289-96. [PubMed: 15671261]

23. Rafanelli C, Roncuzzi R, Milaneschi Y, Tomba E, Colistro MC, Pancaldi LG, et al. Stressful life events, depression and demoralization as risk factors for acute coronary heart disease. Psychother Psychosom 2005;74:179-84. [PubMed: 15832069]

24. Adler NE, Rehkopf DH. U.S. Disparities in Health: Description, Causes, and Mechanisms. Annu Rev Public Health 2008;29:235-52. [PubMed: 18031225]

25. Rasmussen KM, Hilson JA, Kjolhede CL. Obesity may impair lactogenesis II. J Nutr 2001;131:3009S-11S. [PubMed: 11694637]

26. Noble S. Maternal employment and the initiation of breastfeeding. Acta Paediatr 2001;90:423-8. [PubMed: 11332935]

27. Martin RM, Ben-Shlomo Y, Gunnell D, Elwood P, Yarnell JW, Davey Smith G. Breast feeding and cardiovascular disease risk factors, incidence, and mortality: the Caerphilly study. J Epidemiol Community Health 2005;59:121-9. [PubMed: 15650143] 


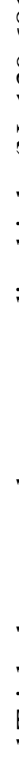




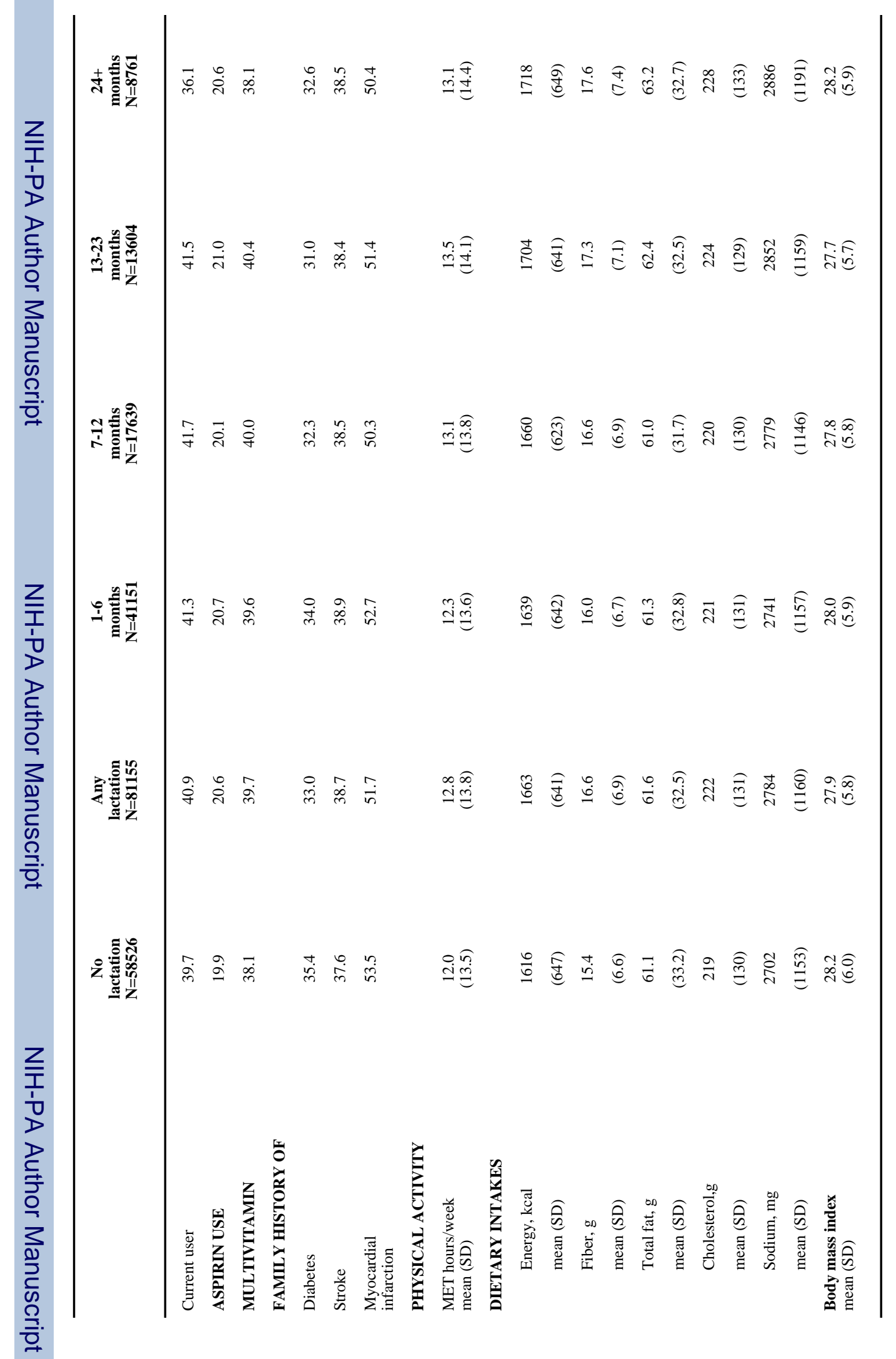




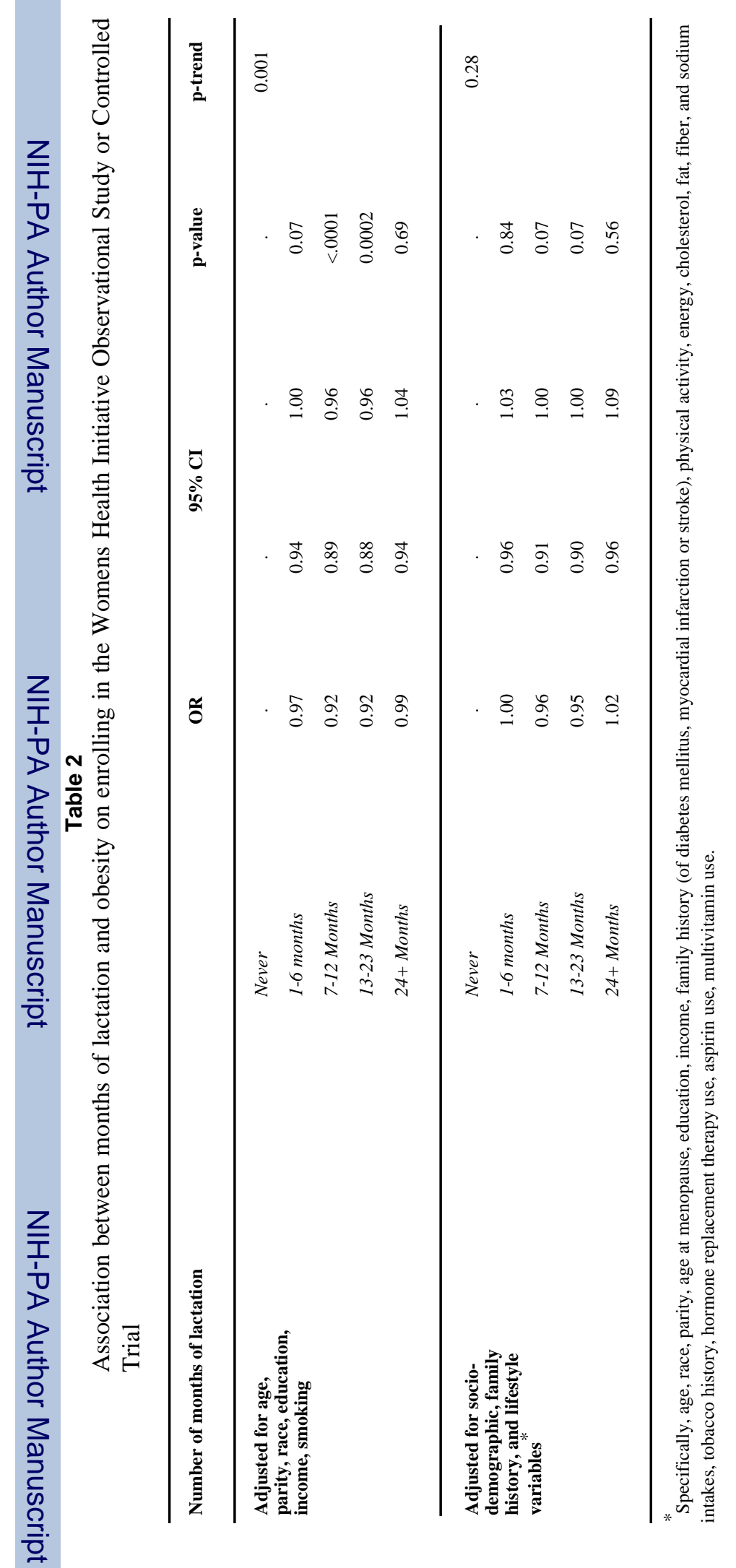

Obstet Gynecol. Author manuscript; available in PMC 2010 May 1. 
Table 3

Association between duration of lactation and self-reported history of Hypertension, Diabetes, or Hyperlipidemia on enrolling in the Womens Health Initiative Observational Study and Controlled Trial

\begin{tabular}{|c|c|c|c|c|}
\hline & & Hypertension & Diabetes & Hyperlipidemia \\
\hline \multicolumn{2}{|c|}{ Number of Months of Lactation } & OR $(95 \% \mathrm{CI})$ & OR $(95 \% \mathrm{CI})$ & OR $(95 \% \mathrm{CI})$ \\
\hline \multirow{6}{*}{$\begin{array}{c}\text { Adjusted for } \\
\text { socio- } \\
\text { demographic, } \\
\text { family history, } \\
\text { and lifestyle } \\
\text { variables }\end{array}$} & Never & Referent & . & . \\
\hline & 1-6 Months & $0.95(0.92-0.98)$ & $0.92(0.85-0.99)$ & $0.93(0.89-0.97)$ \\
\hline & 7-12 Months & $0.88(0.84-0.91)$ & $0.87(0.78-0.97)$ & $0.87(0.82-0.93)$ \\
\hline & 13-23 Months & $0.89(0.84-0.93)$ & $0.74(0.65-0.84)$ & $0.81(0.76-0.87)$ \\
\hline & 24+ Months & $0.87(0.82-0.93)$ & $0.89(0.77-1.02)$ & $0.80(0.74-0.87)$ \\
\hline & $P$ for trend & $<.0001$ & $<.0001$ & $<.0001$ \\
\hline \multirow{6}{*}{$\begin{array}{c}\text { Adjusted for } \\
\text { above plus } \\
\text { Body Mass } \\
\text { Index }^{\dagger}\end{array}$} & Never & Referent & . & . \\
\hline & 1-6 Months & $0.95(0.92-0.98)$ & $0.91(0.84-0.99)$ & $0.93(0.89-0.97)$ \\
\hline & 7-12 Months & $0.88(0.84-0.92)$ & $0.87(0.78-0.97)$ & $0.88(0.83-0.94)$ \\
\hline & 13-23 Months & $0.89(0.84-0.93)$ & $0.75(0.66-0.85)$ & $0.81(0.76-0.87)$ \\
\hline & $24+$ Months & $0.87(0.82-0.92)$ & $0.88(0.76-1.01)$ & $0.80(0.73-0.87)$ \\
\hline & $P$ for trend & $<.0001$ & $<.0001$ & $<.0001$ \\
\hline
\end{tabular}

* Specifically, age, race, parity, age at menopause, education, income, family history (of diabetes mellitus, myocardial infarction or stroke), physical activity, energy, cholesterol, fat, fiber, and sodium intakes, tobacco history, hormone replacement therapy use, aspirin use, multivitamin use.

${ }^{+}$adjusted for 3 categories of body mass index (BMI): $<25,25$ to $<30$, and $\geq 30$. 
Table 4

Association between Duration of Lactation and Cardiovascular Disease (CVD) among participants in the Womens Health Initiative Observational Study and Controlled Trial

\begin{tabular}{|c|c|c|c|}
\hline \multicolumn{2}{|c|}{ Number of Months of Lactation } & $\begin{array}{c}\text { Prevalent CVD } \\
\text { OR }(95 \% \text { CI })\end{array}$ & $\begin{array}{r}\text { Incident CVD } \\
\text { HR }(95 \% \text { CI })\end{array}$ \\
\hline \multirow{6}{*}{$\begin{array}{l}\text { Univariable } \\
\text { models }\end{array}$} & Never & Referent & Referent \\
\hline & 1-6 Months & $1.11(1.06-1.15)$ & $1.08(1.03-1.13)$ \\
\hline & 7-12 Months & $0.94(0.88-0.99)$ & $0.92(0.86-0.98)$ \\
\hline & 13-23 Months & $0.90(0.85-0.96)$ & $0.93(0.86-1.00)$ \\
\hline & $24+$ Months & $0.99(0.92-1.07)$ & $0.96(0.88-1.05)$ \\
\hline & P for trend & 0.007 & 0.01 \\
\hline \multirow{6}{*}{$\begin{array}{l}\text { Adjusted for } \\
\text { socio- } \\
\text { demographic, } \\
\text { family history, } \\
\text { and lifestyle } \\
\text { variables }\end{array}$} & Never & Referent & Referent \\
\hline & 1-6 Months & $1.03(0.97-1.08)$ & $1.03(0.98-1.08)$ \\
\hline & 7-12 Months & $0.94(0.87-1.01)$ & $0.97(0.90-1.03)$ \\
\hline & 13-23 Months & $0.92(0.85-1.00)$ & $0.98(0.91-1.05)$ \\
\hline & $24+$ Months & $0.86(0.89-0.98)$ & $0.93(0.85-1.02)$ \\
\hline & $P$ for trend & 0.003 & 0.10 \\
\hline \multirow{6}{*}{$\begin{array}{l}\text { Adjusted for } \\
\text { above plus Body } \\
\text { Mass Index }\end{array}$} & Never & Referent & Referent \\
\hline & 1-6 Months & $1.03(0.98-1.09)$ & $1.03(0.98-1.08)$ \\
\hline & 7-12 Months & $0.95(0.88-1.02)$ & $0.97(0.90-1.04)$ \\
\hline & 13-23 Months & $0.93(0.85-1.01)$ & $0.98(0.91-1.05)$ \\
\hline & $24+$ Months & $0.89(0.80-0.98)$ & $0.93(0.85-1.02)$ \\
\hline & P for trend & 0.005 & 0.12 \\
\hline
\end{tabular}

\footnotetext{
* Cardiovascular disease on enrollment was identified by a self-reported history of myocardial infarction, angina, congestive heart failure, peripheral arterial disease, revascularization, or stroke.

In

Incident cardiovascular disease (coronary heart disease, stroke, congestive heart failure, angina, peripheral vascular disease, carotid artery disease, and coronary revascularization) was validated by physician adjudication of medical records over 7.9 years of follow up.

***

Specifically, age, race, parity, age at menopause, education, income, family history (of diabetes mellitus, myocardial infarction or stroke), physical activity, energy, cholesterol, fat, fiber, and sodium intakes, tobacco history, hormone replacement therapy use, aspirin use, multivitamin use.

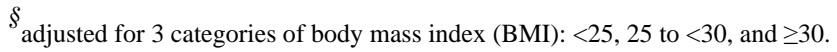




\section{Table 5}

Association between duration of lactation and prevalence of cardiovascular risk factors, ${ }^{*}$ with additional adjustment for weight at age 18, birth weight, and whether a woman was breastfed as an infant

\begin{tabular}{|c|c|c|c|c|}
\hline \multicolumn{2}{|c|}{ Number of Months of Lactation } & \multirow{2}{*}{$\begin{array}{l}\text { OR } \\
\text { Referent }\end{array}$} & \multirow[t]{2}{*}{ 95\% CI } & \multirow{2}{*}{$\begin{array}{l}\text { P for trend } \\
0.67\end{array}$} \\
\hline Obesity & Never & & & \\
\hline & 1-6 months & 1.00 & $(0.95-1.05)$ & \\
\hline & 7-12 Months & 0.94 & $(0.87-1.00)$ & \\
\hline & 13-23 Months & 0.94 & $(0.87-1.02)$ & \\
\hline & $24+$ Months & 1.07 & $(0.98-1.18)$ & \\
\hline \multirow[t]{5}{*}{ Hypertension } & Never & Referent & & $<.0001$ \\
\hline & 1-6 months & 0.95 & $(0.91-0.99)$ & \\
\hline & 7-12 Months & 0.87 & $(0.82-0.93)$ & \\
\hline & 13-23 Months & 0.90 & $(0.85-0.97)$ & \\
\hline & $24+$ Months & 0.88 & $(0.81-0.95)$ & \\
\hline \multirow[t]{5}{*}{ Diabetes } & Never & Referent & & 0.02 \\
\hline & 1-6 months & 0.94 & $(0.84-1.04)$ & \\
\hline & 7-12 Months & 0.91 & $(0.78-1.06)$ & \\
\hline & 13-23 Months & 0.69 & $(0.58-0.84)$ & \\
\hline & $24+$ Months & 0.99 & $(0.82-1.19)$ & \\
\hline \multirow[t]{5}{*}{ Hyperlipidemia } & Never & Referent & & $<.0001$ \\
\hline & 1-6 months & 0.91 & $(0.86-0.96)$ & \\
\hline & 7-12 Months & 0.84 & $(0.78-0.91)$ & \\
\hline & 13-23 Months & 0.80 & $(0.73-0.87)$ & \\
\hline & $24+$ Months & 0.83 & $(0.74-0.93)$ & \\
\hline \multirow{5}{*}{$\begin{array}{l}\text { Cardiovascular } \\
\text { disease }\end{array}$} & Never & Referent & & 0.26 \\
\hline & 1-6 months & 1.06 & $(0.99-1.13)$ & \\
\hline & 7-12 Months & 0.97 & $(0.88-1.06)$ & \\
\hline & 13-23 Months & 0.98 & $(0.88-1.09)$ & \\
\hline & 24+ Months & 0.94 & $(0.82-1.07)$ & \\
\hline
\end{tabular}

* These analyses include only participants in the WHI observational study ( $\mathrm{N}=78825)$ who provided information on their weight at age 18 , birth weight, and whether they were breastfed as an infant. All models are adjusted for age, race, parity, smoking, education, income, age at menopause, physical activity; diet (energy, cholesterol, fat, fiber, and sodium intakes), use of postmenopausal hormone therapy, aspirin, and, multivitamins, and family history of diabetes, myocardial infraction, or stroke, in addition to these variables. 